Journal of Engineering and Applied Sciences 14 (16): 5782-5788, 2019

ISSN: 1816-949X

(C) Medwell Journals, 2019

\title{
Control Decoupled MRAC for Product Concentration in a Distillation Binary Column
}

\author{
Sebastian Useche, Angelica Orjuela and Dario Amaya \\ Virtual Applications Group (GAV), Nueva Granada Military University (UMNG), Bogota, Colombia \\ \{U1801739,U1801708,dario.amaya\}@unimilitar.edu.co
}

\begin{abstract}
Refining industry uses advanced control techniques because of the need to improve processes and get better quality products at lower cost. Distillation consumes much energy, for that reason, new control alternatives that provide better process efficiency are being sought. The new control techniques are oriented to improve response times and reduce system the energy consumption. The application of adaptive controllers for this type of process opens a wide field of study to verify their versatility and robustness using simulation programs, through these is easy to test the effectiveness of the controller and determine, if their behavior are the desired. In this study, the performance of a MIMO MRAC controller is shown from Lyapunov laws applied to a binary distillation column, introducing the mathematical development of the plant, its linearization, decoupling and obtaining the controller functions. Also, implementation of the scheme plant-controller is performed and its subsequent simulation, analyzing the behavior of the responses to verify the effectiveness of this type of controller.
\end{abstract}

Key words: Distillation, multivariable, MRAC, Lyapunov, MIMO, scheme plant

\section{INTRODUCTION}

The distillation processes are looking the separation of substances, manipulating their boiling point and condensation. The energy used to obtain the products, is considered the highest in chemical processes (Seban et al., 2015). Refining industries use advanced control techniques to improve the product quality and reduce operating costs (Yamashita et al., 2016).

The interaction between variables make these types of processes multivariable, getting hard the application of control techniques (Morilla et al., 2013). The distillation columns have been point research in recent years, where they have developed methods to decouple in independent groups, forming loops for working with decentralized systems and facilitating the implementation of control systems (Dorrah et al., 2012).

Adaptive control is usually used in processes where some parameters are unknown and cannot be obtained with certainty the total plant model (Selivanov et al., 2016) to distillation processes have been applied this type of controllers where have advantages over the dynamic response of the system compared to traditional controllers (Murlidhar and Jana, 2007).

The Model Reference Adaptive Control (MRAC) establishes a model to be followed by the plant, it has to meet appropriate requirements for operation based on a simple structure using a fast and stable configuration (Zhang et al., 2015).
The MRAC works to ensure that the error converges to zero, using an adaptation algorithm to reference model which does not require the full knowledge of the plant (Montanaro and Olm, 2015). A solution to algorithm is the implementation of the law of Lyapunov (Costa et al., 2003).

Some research related to the theme are design of an adaptive predictive control strategy for crude oil atmospheric distillation process where the proposed methodology to coupled system reduces the complexity of the control structures (Raimondi et al., 2015). On adaptive optimizing control of an ideal reactive column was demonstrated that the scheme is able to successfully track the optimum operating point of the system (Valluru et al., 2015). Synthesis of nonlinear adaptive controller for a batch distillatio, the controller with a simple structure and easy adjustment, obtained good results in controlling the concentration (Jana, 2007).

Next, it is going to be presented, the design of a MRAC MIMO system control for binary distillation column. The state space model is applied linearization and decoupling matrices, from this, calculations are performed to develop the adaptive controller using the laws of Lyapunov. The responses obtained from the concentration of background and distillate are analyzed to determine the efficiency of this type of controller.

Corresponding Author: Sebastian Useche, Virtual Applications Group (GAV), Nueva Granada Military University (UMNG), Bogota, Colombia, \{U1801739, U1801708, dario.amaya\}@unimilitar.edu.co 


\section{MATERIALS AND METHODS}

Model of the distillation column: The design of adaptive control system for a binary distillation requires knowledge of the behavior of the plant (Klau; et al., 2015) in order to determine the reference model is going to be propose the nonlinear model based on Fig. 1

The vapor-liquid equilibrium is applied by Eq. 1 to obtain the linear model. The $\mathrm{xn}$ is the concentration of liquid and yn vapor concentration as a relative volatility $\alpha$ (Mehta et al., 2011). Considering the above is expanded using the Taylor series, the difference $x n-\overline{x n}$ can be assumed minimum (Sivananaithaperumal and Baskar, 2014):

$$
\mathrm{yn}=\frac{\mathrm{axn}}{1+(\mathrm{a}-1) \mathrm{xn}}
$$

For the calculation of the model proposed by Skogestad (1991, 1997), the following values to system variables are established.

- Methanol-water mixture

- $\quad$ Dishes $(\mathrm{NT})=41$

- $\quad$ Dish Feeding (NF) $=21$

- $\quad$ Alpha constant $=1.5$

- Feed Flow $(\mathrm{F})=1 \mathrm{~mol} / \mathrm{min}$

- Volatile concentration $(\mathrm{ZF})=0.8 \mathrm{~mol}$ fraction

- $\quad$ Reboiler flow $(\mathrm{R})=2.706 \mathrm{~mol} / \mathrm{min}$

- $\quad$ Feed state $(\mathrm{Qf})=1$ (Saturated liquid)

The Linearized material balance for each plate would be equal to presented in Eq. 2:

$$
\begin{aligned}
& \text { Mixl }=\mathrm{L}_{\mathrm{i}-1} \partial \mathrm{x}_{\mathrm{i}-1}-\left(\mathrm{L}_{\mathrm{i}}+\mathrm{KiVi}\right) \partial \mathrm{x}_{\mathrm{i}}+ \\
& \mathrm{K}_{\mathrm{i}-1} \mathrm{~V}_{\mathrm{i}-1} \partial \mathrm{x}_{\mathrm{i}}+\left(\mathrm{x}_{\mathrm{i}+1}-\mathrm{xi}\right)-\left(\mathrm{yi}-\mathrm{y}_{\mathrm{i}-1}\right) \partial \mathrm{V}
\end{aligned}
$$

Where:

$$
\mathrm{Ki}=\frac{\partial \mathrm{y}_{\mathrm{i}}}{\partial \mathrm{x}_{\mathrm{i}}}=\frac{\alpha}{(1+(\alpha-1) \mathrm{xi})^{2}}
$$

yi, xi, Li y Vi are steady-state values at operation point. Writing in state space variables:

$$
\left\{\begin{array}{c}
\dot{x}=A x+B u \\
y=C x
\end{array}\right\}
$$

Where:

$\mathrm{x}=[\partial \mathrm{x}(\mathrm{i}), \ldots, \partial \mathrm{x}(\mathrm{n}+1)]^{\mathrm{T}}=$ Composition dishes

$\mathrm{Ut}=[\partial \mathrm{L}, \partial \mathrm{V}]^{\mathrm{T}} \quad=$ Manipulated variables input $\mathrm{yt}=[\partial \mathrm{xD}, \partial \mathrm{xB}]^{\mathrm{T}} \quad=$ Output controlled variables

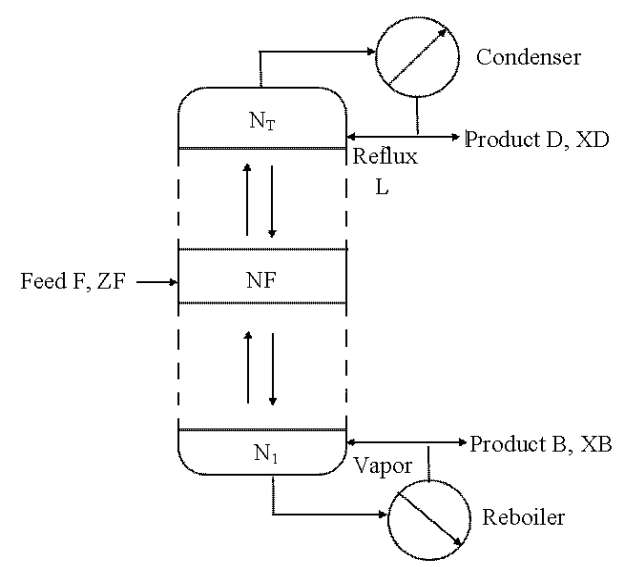

Fig. 1: Schematic binary distillation column

A is tridiagonal matrix of order NT $=41$ is calculated taking account Eq. 5 (Selivanov et al., 2016; Zhang et al., 2015) where $i=1$ :

$$
\begin{aligned}
& A(1,1)=\frac{-V(1)}{M(1)} \\
& A(1,2)=\frac{V(2)^{*} K(2)}{M(2)}
\end{aligned}
$$

With $1<\mathbf{i}<\mathrm{NT}-1$ :

$$
\begin{aligned}
& A(i, i-1)=\frac{L(i)}{M(i)} \\
& A(i, i)=\frac{L(i)+K(i) V(i)}{M(i)} \\
& A(i, i+1)=\frac{K(i+1) V(i)}{M(i)}
\end{aligned}
$$

For $\mathrm{i}=\mathrm{NT}$ :

$$
\begin{aligned}
& A(N T, N T-1)=\frac{L(N T)}{M(N T)} \\
& A(N T, N T)=\frac{-0.5+K(N T) V(N T)}{M(N T)}
\end{aligned}
$$

The matrix $\mathrm{B}[\mathrm{NT}, 2]$ is calculated considering the Eq. 8 and 9 . With $\mathrm{i}=1$ :

$$
\mathrm{B}(1,1)=0 \mathrm{y} \mathrm{B}(1,2)=0
$$

For $1<\mathbf{i}<\mathrm{NT}-1, \mathrm{NT}$ is the number of dishes:

$$
\begin{aligned}
& B(i, 1)=\frac{(X(i-1)-X(i))}{M(i)} \\
& B(i, 2)=\frac{(Y(i+1)-Y(i))}{M(i)}
\end{aligned}
$$


For $\mathrm{i}=\mathrm{NT}$ :

$$
\begin{aligned}
& B(N T, 1)=\frac{(X(N T-1)-X(N T))}{M(N T)} \\
& B(N T, 2)=\frac{(X(N T)-Y(N T))}{M(N T)}
\end{aligned}
$$

The output matrix $\mathrm{C}$ is:

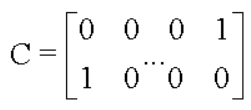

The system can be expressed as a reduced system of 2 inputs and 2 outputs, using the following Eq. 11:

$$
\left[\begin{array}{l}
\mathrm{xD} \\
\mathrm{xB}
\end{array}\right]=\frac{1}{1+\tau_{\mathrm{c}} \mathrm{s}} \mathrm{G}(0)\left[\begin{array}{l}
\mathrm{L} \\
\mathrm{V}
\end{array}\right]
$$

where, $G(0)=-\mathrm{CA}^{-1} \mathrm{~B}$ and $\tau_{\mathrm{c}}$ represents the time constant calculated in Eq. 12:

$$
\tau_{\mathrm{c}}=\frac{\mathrm{M}_{\mathrm{I}}}{\mathrm{I}_{\mathrm{s}} \ln _{\mathrm{s}}}+\frac{\mathrm{M}_{\mathrm{D}}\left(1-\mathrm{x}_{\mathrm{D}}\right) \mathrm{x}_{\mathrm{D}}}{\mathrm{I}_{\mathrm{s}}}+\frac{\mathrm{M}_{\mathrm{B}}\left(1-\mathrm{x}_{\mathrm{B}}\right) \mathrm{x}_{\mathrm{B}}}{\mathrm{I}_{\mathrm{s}}}
$$

Variables represent the amount of liquid in the column $\left(\mathrm{M}_{1}\right)$, condenser $(\mathrm{MD})$ and reboiler $(\mathrm{MB})$; $\mathrm{I}_{\mathrm{s}}$ is the sum of impurities and y $\mathrm{S}$ is the separation factor. With $\tau_{\mathrm{c}}=1.975(\mathrm{~h})$. Equation 13 illustrates equality for obtaining the matrix $\mathrm{P}$ :

$$
\frac{1}{1+\tau_{c} s} \mathrm{G}(0)=\left[\begin{array}{ll}
P_{11}(s) & P_{12}(s) \\
P_{21}(s) & P_{22}(s)
\end{array}\right]
$$

Where:

$$
\operatorname{Pij}(\mathrm{s})=\frac{\mathrm{Ke}^{-\lambda s}}{\tau \mathrm{s}+1}(\mathrm{i}, \mathrm{j}=1,2)
$$

Applying the function, matrix $\mathrm{P}$ is obtained:

$$
\left[\begin{array}{ll}
\mathrm{P}_{11}(\mathrm{~s}) & \mathrm{P}_{12}(\mathrm{~s}) \\
\mathrm{P}_{21}(\mathrm{~s}) & \mathrm{P}_{22}(\mathrm{~s})
\end{array}\right]=\left[\begin{array}{cc}
\frac{12.8 \mathrm{e}^{-\mathrm{s}}}{16.7 \mathrm{~s}+1} & \frac{-18.9 \mathrm{e}^{-3 \mathrm{~s}}}{21 \mathrm{~s}+1} \\
\frac{6.6 \mathrm{e}^{-7 \mathrm{~s}}}{10.9 \mathrm{~s}+1} & \frac{-19.4 \mathrm{e}^{-3 \mathrm{~s}}}{14.4 \mathrm{~s}+1}
\end{array}\right]
$$

The complete linear system represented in a $2 \times 2$ system in the frequency domain is:

$$
\left[\begin{array}{l}
\mathrm{Xd}(\mathrm{s}) \\
\mathrm{Xb}(\mathrm{s})
\end{array}\right]=\left[\begin{array}{cc}
\frac{12.8 \mathrm{e}^{-\mathrm{s}}}{16.7 \mathrm{~s}+1} & \frac{-18.9 \mathrm{e}^{-3 \mathrm{~s}}}{21 \mathrm{~s}+1} \\
\frac{6.6 \mathrm{e}^{-7 \mathrm{~s}}}{10.9 \mathrm{~s}+1} & \frac{-19.4 \mathrm{e}^{-3 \mathrm{~s}}}{14.4 \mathrm{~s}+1}
\end{array}\right]\left[\begin{array}{l}
\mathrm{L}(\mathrm{s}) \\
\mathrm{V}(\mathrm{s})
\end{array}\right]
$$

where, $\mathrm{Xd}$ and $\mathrm{Xb}$ represent the mole fraction of methanol-water mixture, in the distillate and background. $\mathrm{L}$ is the liquid flow from the condenser (reflux) and $\mathrm{V}$ the reboiler vapor flow.

To control the distillation column is necessary calculate a decoupling functions $\mathrm{D}_{12}(\mathrm{~s})$ y $\mathrm{D}_{21}(\mathrm{~s})$, in order to compensate the interactions between system variables and obtain independent control loops. Equation 17 and 18 show the calculation:

$$
\begin{aligned}
& D_{21}(s)=-\frac{P_{21}(s)}{P_{22}(s)}=\frac{33 \mathrm{e}^{-4 s}(14.4 \mathrm{~s}+1)}{97(10.9 \mathrm{~s}+1)} \\
& \mathrm{D}_{12}(\mathrm{~s})=-\frac{\mathrm{P}_{12}(\mathrm{~s})}{\mathrm{P}_{11}(\mathrm{~s})}=\frac{189 \mathrm{e}^{-2 \mathrm{~s}}(16.7 \mathrm{~s}+1)}{128(21 \mathrm{~s}+1)}
\end{aligned}
$$

To set the controller, estimate the model taking into consideration the coupling according to the Eq. 19:

$$
\left[\begin{array}{l}
\mathrm{Xd}(\mathrm{s}) \\
\mathrm{Xb}(\mathrm{s})
\end{array}\right]=\left[\begin{array}{cc}
\mathrm{T}_{11}(\mathrm{~s}) & 0 \\
0 & \mathrm{~T}_{22}(\mathrm{~s})
\end{array}\right]\left[\begin{array}{l}
\mathrm{u} 1(\mathrm{~s}) \\
\mathrm{u} 2(\mathrm{~s})
\end{array}\right]
$$

$\mathrm{T}_{11}$ y $\mathrm{T}_{22}$ express independent control loops as illustrated in Eq. 20 and 21 :

$$
\begin{aligned}
& \mathrm{T}_{11}(\mathrm{~s})=\mathrm{P}_{11}(\mathrm{~s})+\mathrm{P}_{12}(\mathrm{~s}) \mathrm{D}_{21}(\mathrm{~s}) \\
& \mathrm{T}_{22}(\mathrm{~s})=\mathrm{P}_{22}(\mathrm{~s})+\mathrm{P}_{21}(\mathrm{~s}) \mathrm{D}_{12}(\mathrm{~s})
\end{aligned}
$$

MRCA using Lyapunov stability: The MRCA is performed based on the development of Lyapunov stability exhibited by Astrom and Wittenmark (1995) y and its implementation for a control system by Anbu and Jaya (2014).

The reference model and the process are expressed in first order differential Eq. 22 and 23:

$$
\begin{gathered}
\frac{d y_{m}}{d t}=-a_{m} y_{m}+b_{m} u_{c} \\
\frac{d y}{d t}=-a y+b u
\end{gathered}
$$

The Lyapunov control law is the difference between the input signal and the output of the plant, multiplied by the parameter $\theta$. The error is the subtraction between the process and the reference model. Equation 24 and 25 express the above: 


$$
\begin{gathered}
\mathrm{u}=\theta_{1} \mathrm{u}_{\mathrm{c}}-\theta_{2} \mathrm{y} \\
\mathrm{e}=\mathrm{y}-\mathrm{y}_{\mathrm{m}}
\end{gathered}
$$

Deriving the error:

$$
\frac{d e}{d t}=-a_{m}-\left(b \theta_{2}+a-a_{m}\right) y+\left(b \theta_{1}-b_{m}\right) u
$$

The error converges to zero when the parameters obtained the values shown in the following Eq. 27 :

$$
\begin{gathered}
\theta_{1}=\frac{\mathrm{b}_{\mathrm{m}}}{\mathrm{b}} \\
\theta_{1}=\frac{\mathrm{a}_{\mathrm{m}}-\mathrm{a}}{\mathrm{b}}
\end{gathered}
$$

The quadratic function of Eq. 29 is introduced, to determine the Lyapunov stability and calculate the parameters of adaptation:

$$
\mathrm{V}\left(\mathrm{e}, \theta_{1}, \theta_{2}\right)=\frac{1}{2}\left(\mathrm{e}^{2}+\frac{1}{\mathrm{~b} \gamma}\left(\mathrm{b} \theta_{2}+\mathrm{a}-\mathrm{a}_{\mathrm{m}}\right)^{2}+\frac{1}{\mathrm{~b} \gamma}\left(\mathrm{b} \theta_{1}-\mathrm{b}_{\mathrm{m}}\right)^{2}\right)
$$

The function $\mathrm{V}$ is zero when the error is zero and the parameters comply with the set values, the function derivative is illustrated in Eq. 30 :

$$
\frac{\mathrm{dV}}{\mathrm{dt}}=\mathrm{e} \frac{\mathrm{de}}{\mathrm{dt}}+\frac{1}{\gamma}\left(\mathrm{b} \theta_{2}+\mathrm{a}-\mathrm{a}_{\mathrm{m}}\right) \frac{\mathrm{d} \theta_{2}}{\mathrm{dt}}+\frac{1}{\gamma}\left(\mathrm{b} \theta_{1}-\mathrm{b}_{\mathrm{m}}\right) \frac{\mathrm{d} \theta_{1}}{\mathrm{dt}}
$$

If the function has a negative derivative, it is considered a Lyapunov function. In Eq. 31 is shown the expression $-\mathrm{a}_{\mathrm{m}} \mathrm{e}^{2}$ replacing values of the Eq. 24-26:

$$
\frac{d V}{d t}=-a_{m} e^{2}+\frac{1}{\gamma}\left(b \theta_{2}+a-a_{m}\right)\left(\frac{d \theta_{2}}{d t}-\gamma y e\right)+\frac{1}{\gamma}\left(b \theta_{1}-b_{m}\right)\left(\frac{d \theta_{1}}{d t}+\gamma u_{c} e\right)
$$

For to this derivate become negative is necessary to update the values of the parameters, the derivative will be equal to $-\mathrm{a}_{\mathrm{m}} \mathrm{e}^{2}$ when the following equations are satisfied:

$$
\begin{aligned}
& \frac{d \theta_{1}}{d t}=-\gamma u_{c} \mathrm{e} \\
& \frac{d \theta_{2}}{d t}=-\gamma y e
\end{aligned}
$$

Therefore, the value of the derivative is semi-defined, where error values and the parameters are limited, the value $\gamma$ can be varied to adjust the adaptation of the system. In this way the method solves the Lyapunov stability problems presented using gradients.

The adaptation of the system to a second order plant is the extension of the previous method where a new parameter is included to the control law as expressed in Eq. 34:

$$
\mathrm{u}=\theta_{1} \mathrm{u}_{\mathrm{c}}-\theta_{2} \mathrm{y}-\theta_{3} \dot{\mathrm{y}}
$$

Using the method, the derivative is obtained:

$$
\begin{aligned}
& \frac{d \theta_{1}}{d t}=\frac{-\gamma_{1}}{b} u_{c} e \\
& \frac{d \theta_{2}}{d t}=\frac{\gamma_{2}}{b} y e \\
& \frac{d \theta_{3}}{d t}=\frac{\gamma_{3}}{b} \dot{y} e
\end{aligned}
$$

Applying the integral to the previous functions, the parameters for adaptation of the plant are as shown below:

$$
\begin{aligned}
& \theta_{1}=\frac{-\gamma_{1}}{b} \int u_{c} \text { edt }+\theta_{1}(0) \\
& \theta_{2}=\frac{\gamma_{2}}{b} \int y e d t+\theta_{2}(0) \\
& \theta_{3}=\frac{\gamma_{3}}{b} \int \dot{y} e d t+\theta_{3}(0)
\end{aligned}
$$

The reference model representing the desired behavior of the plant. For its design should take into account the response time in open loop and the following Eq. 41:

$$
\begin{gathered}
M R=\frac{w_{n}{ }^{2}}{s^{2}+2 \rho w_{n} s+w_{n}{ }^{2}} \\
w_{n}=\frac{4.6}{\rho t_{s}}
\end{gathered}
$$

The $\rho$ is the damping constant of the system, 4.6 represents the time constant where the plant is maintained within $1 \%$ error.

\section{RESULTS AND DISCUSSION}

Figure 2 shows the whole system including the MRAC, the plant, decoupling matrices and disturbances. The controller represents the Eq. 38-40. The values used are observed in Table 1. 


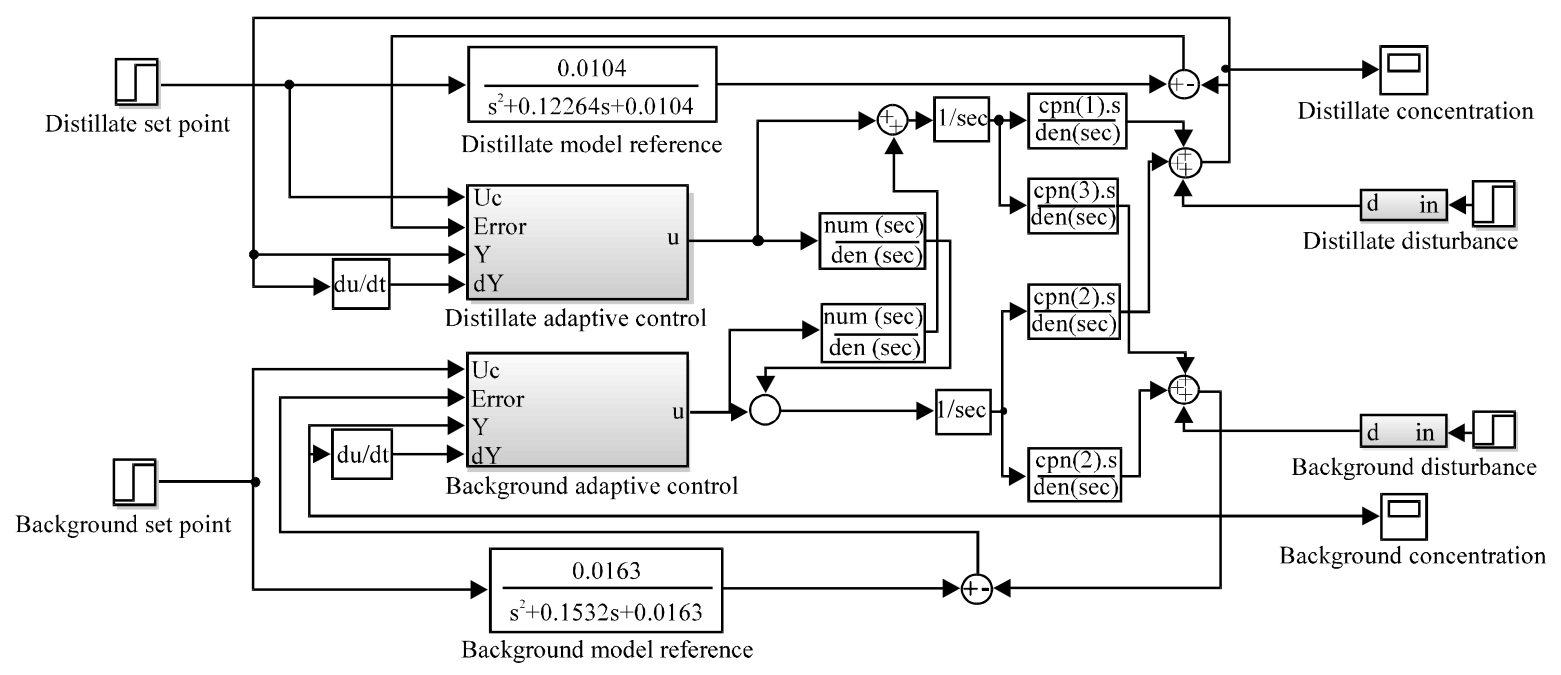

Fig. 2: Schematic plant-controller

Table 1: Parameters of controller

\begin{tabular}{ll}
\hline Parameters & Values \\
\hline $\begin{array}{l}\text { Distillate controller } \\
\gamma_{1} / \mathrm{b}, \gamma_{2} / \mathrm{b}, \gamma_{3} / \mathrm{b}\end{array}$ & $0.007,-0.01,-0.01$ \\
Background contr oller & \\
$\gamma_{1} / \mathrm{b}, \gamma_{2} / \mathrm{b}, \gamma_{3} \mathrm{~b}$ & $-0.03,0.38,0.38$ \\
\hline
\end{tabular}

The reference models of Eq. 43 and 44 were calculated with $\rho=0.6$ and with open-loop step response of $75 \mathrm{sec}$ for distillate and $60 \mathrm{sec}$ for background:

$$
\begin{aligned}
& \mathrm{MR}_{\mathrm{d}}=\frac{0.1022^{2}}{\mathrm{~s}^{2}+2^{*} 0.6^{*} 0.1022 \mathrm{~s}+0.1022^{2}} \\
& \mathrm{MR}_{\mathrm{f}}=\frac{0.1277^{2}}{\mathrm{~s}^{2}+2^{*} 0.6^{*} 0.1277 \mathrm{~s}+0.1277^{2}}
\end{aligned}
$$

In Fig. 3 the background concentration is observed, compared with the reference signal in molar fraction (sp), in an interval of $300 \mathrm{sec}$.

The background concentration has a stabilization time of $3.71 \mathrm{~min}$ and a $12.16 \%$ of overshoot. In Fig. 4, the control signal is observed for background concentration of 0.3 at an interval of $600 \mathrm{sec}$.

In Fig. 5, the distillate concentration versus the reference signal in an interval $300 \mathrm{sec}$ is observed. The distillate concentration has a stabilization time of $4.28 \mathrm{~min}$ and $12.94 \%$ overshoot. In Fig. 6 the control signal is observed for distillate concentration of 0.7 at an interval of $600 \mathrm{sec}$.

The control signals are low because the loops are adapted to the models as illustrated in Fig. 7 with the distillate concentration. Errors are the differences between

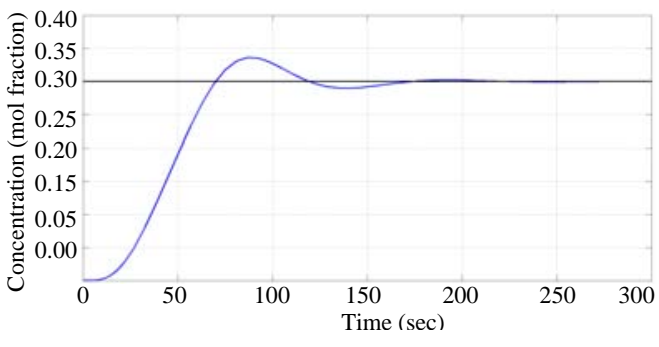

Fig. 3: Concentration background (Blue) vs. sp (Black)

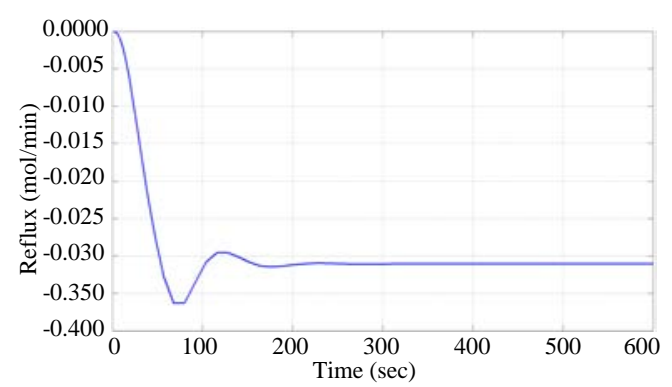

Fig. 4: Control signal for the background

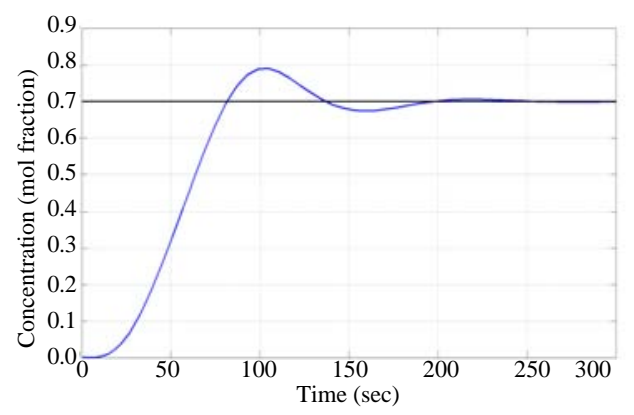

Fig. 5: Distillate concentration (Blue) vs. sp (Black) 


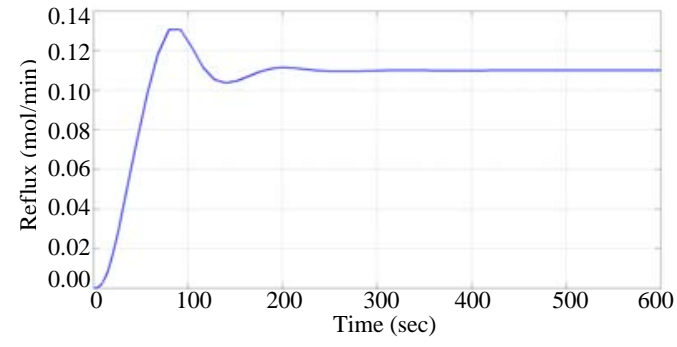

Fig. 6: Control signal for the distillate

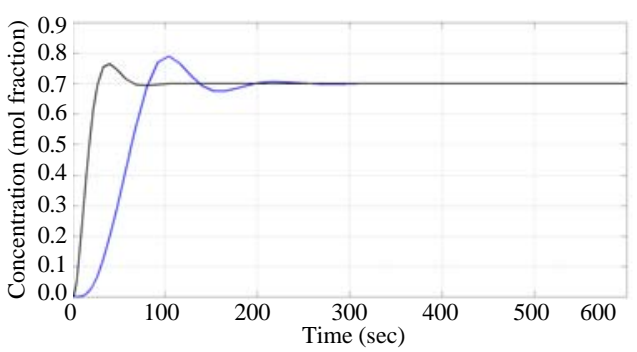

Fig. 7: Reference model (Black) vs. distillate concentration (Blue)

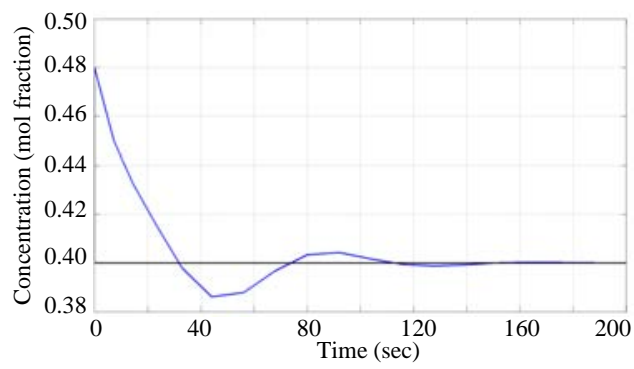

Fig. 8: Variation in the background concentration (Black vs. Blue)

plants in an instant of time; this prevents an excess control because variations are lower than when a constant reference is used.

To analyze the behavior of the developed controller, is compared with a PID fuzzy exhibited by Mishra et al. (2015), simulating the same changes made to the fuzzy control.

To the background concentration was applied a variation from $0.48-0.4$, the fuzzy control has a stabilization time of $4.8 \mathrm{~min}$; the adaptive controller obtains $2.66 \mathrm{~min}$, illustrated in Fig. 8.

The variation in concentration of distillate is from 0.9-0.8. MRAC stabilizes at $2 \mathrm{~min}$ as shown in Fig. 9 while the PID fuzzy stabilized at $2.4 \mathrm{~min}$.

MRAC controller improves the stabilization time, having designed a reference model and adaptability algorithm generated from a stability law.

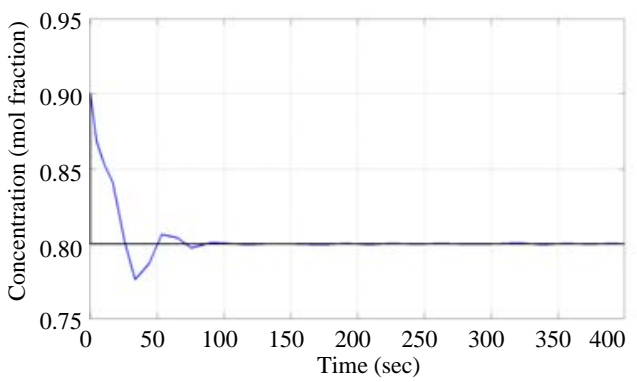

Fig. 9: Variation in the distillate concentration (Black vs. Blue)

\section{CONCLUSION}

Based on the Lyapunov stability laws; the controller design and system reference models was performed. The results demonstrate the feasibility of this application to distillation processes.

To implement a MRAC is necessary to know the behavior of the open loop plant to design the appropriate reference model for adaptation.

One advantage of adaptive controllers is that have good stability and robustness without requiring extensive knowledge of the mathematical model from the plant unlike predictive controllers.

These controllers help to reduce energy consumption by using control signals in function to the variation of a model reference, making them more efficient over traditional controllers.

\section{ACKNOWLEDGEMENTS}

Special thanks to the Research Vice-rectory of the "Universidad Militar Nueva Granada", for financing the project INV_ING_1911 titled "Laboratorio Virtual para el Control del Proceso de Refinación del Petróleo con Realidad Aumentada y Realidad Virtual"project, 2015 year.

\section{REFERENCES}

Anbu, S. and N. Jaya, 2014. Design of adaptive controller based on Lyapunov stability for a CSTR. Intl. J. Electr. Electron. Sci. Eng., 8: 183-186.

Astrom, K.J. and B. Wittenmark, 1995. Adaptive Control. 2nd Edn., Addison-Wesley, Boston, Massachusetts, USA., ISBN:9780201558661, Pages: 574.

Costa, R.R., L. Hsu, A.K. Imai and P. Kokotovic, 2003. Lyapunov-based adaptive control of MIMO systems. Autom., 39: 1251-1257.

Dorrah, H.T., A.M. El-Garhy and M.E. El-Shimy, 2012. PSO based optimized fuzzy controllers for decoupled highly interacted distillation process. Ain Shams Eng. J., 3: 251-266. 
Jana, A.K., 2007. Synthesis of nonlinear adaptive controller for a batch distillation. ISA. Trans., 46: 49-57.

Mehta, I., V. Singh and D.V. Gadre, 2011. Simulation and control of binary distillation column using XMOS technology. Image Proc. Appl. Workshop ICEEA., 21: 228-232.

Mishra, P., V. Kumar and K.P.S. Rana, 2015. A fractional order fuzzy PID controller for binary distillation column control. Expert Syst. Appl., 42: 8533-8549.

Montanaro, U. and J.M. Olm, 2015. Discrete-time integral MRAC with minimal controller synthesis and parameter projection. J. Franklin Inst., 352: 5415-5436.

Morilla, F., J. Garrido and F. Vazquez, 2013. [Multivariate control by decoupling (In Galician)]. Iberoam. Mag. Automatics Ind. Comput., 10: 3-17.

Murlidhar, G.M. and A.K. Jana, 2007. Nonlinear adaptive control algorithm for a multicomponent batch distillation column. Chem. Eng. Sci., 62: 1111-1124.

Raimondi, A., A. Favela-Contreras, F. Beltran-Carbajal, A. Pinon-Rubio and J.L. De La Pena-Elizondo, 2015. Design of an adaptive predictive control strategy for crude oil atmospheric distillation process. Control Eng. Pract., 34: 39-48.

Seban, L., V. Kirubakaran, B.K. Roy and T.K. Radhakrishnan, 2015. GOBF-ARMA based model predictive control for an ideal reactive distillation column. Ecotoxicol. Environ. Saf., 121: 110-115.
Selivanov, A., A. Fradkov and D. Liberzon, 2016. Adaptive control of passifiable linear systems with quantized measurements and bounded disturbances. Syst. Control Lett., 88: 62-67.

Sivananaithaperumal, S. and S. Baskar, 2014. Design of multivariable fractional order PID controller using covariance matrix adaptation evolution strategy. Arch. Control Sci., 24: 235-251.

Skogestad, S., 1991. Modelling and dynamic simulation for process control. Proceedings of the International Seminar on Lecture Notes for Modelling and Optimization of Chemical Processes, August 26-28, 1991, NTH, Trondheim, Norway, pp: $1-30$.

Skogestad, S., 1997. Dynamics and control of distillation columns-a critical survey. Mod. Identif. Control, 18: $177-217$.

Valluru, J., J.L. Purohit, S.C. Patwardhan and S.M. Mahajani, 2015. Adaptive optimizing control of an ideal reactive distillation column. IFAC. Pap. Online, 48: 489-494.

Yamashita, A.S., A.C. Zanin and D. Odloak, 2016. Tuning the model predictive control of a crude distillation unit. ISA Trans., 60: 178-190.

Zhang, S., Y. Feng and D. Zhang, 2015. Application research of MRAC in fault-tolerant flight controller. Procedia Eng., 99: 1089-1098. 